10.2478/v10367-012-0008-6

WLADYSLAW KOC, PIOTR CHROSTOWSKI

Gdansk University of Technology

CEZARY SPECHT

Polish Naval Academy

\title{
FINDING DEFORMATION \\ OF THE STRIGHT RAIL TRACK \\ BY GNSS MEASUREMENTS
}

\begin{abstract}
In 2009, at the Gdansk University of Technology and Polish Naval Academy there has been carried out, for the first time, continuous satellite surveying of railway track by the use of the relative phase method based on the Polish Active Geodetic Network ASG-EUPOS and RTK (GPRS) real time service - NAVGEO. The analysis indicated strong connection between location of GNSS receiver and accuracy of position determination, the horizon obstruction deteriorated accuracy and impacts terrain obstructions, the precise GPS planning process on the position solution. It can be stated that implemented measuring technique opens a whole new perspective on applied research. As proved, it enables very precise determination of basic data definition for railway line modernization design. On-going research works focuses on the GNSS multi-receivers platform evaluation for projecting and stocktaking.

Analyses also focused on the values of deviations of transverse position XTE (Cross Track Error). In order to eliminate the influence of random measurement errors and to obtain the coordinates representing the actual shape of the track, the XTE variable was performed by different statistical and regression methods (least square method - LSM, weighted least squares - WLS, Linear Chebyshev low-pass filtering and fast Fourier transform). The paper presents the result of trial analyses realized on the newly constructed (rectilinear) and old-used up railway lines. The authors were searching the methods for filtering random measurement GNSS errors different from instantaneous shape deformations of the straight rail track.
\end{abstract}

Keywords:

railway track, geometrical layout, satellite surveying GPS, ASG-EUPOS network, coordinates determining, error correction.

\section{INTRODUCTION}

One of the main problems connected with geometrical forming systems of a railway track is the lack of detection range of the whole system activity. This is connected 
with line sections and curves on a railway area which are very often so large that visual evaluation of their shape is impossible. Conventional geodesy requires division of the railway route into smaller examined separately parts. It becomes an additional errors source and a total appraisal of particular geometrical system is difficult. Development of geodesic satellite techniques combined with improving precision of measure GPS (Global Positioning System) induces geodesists to make an attempt to apply GPS technique for the purpose of making inventory of railway tracks. Accessible to researchers at the beginning of the 21 century measurement techniques and development of the RTK (Real Time Kinematics) methods have allowed researchers to obtain measuring accuracy of one centimetre at $1-5 \mathrm{~Hz}$ frequencies with necessity of additional altitude measurement reduction [8].

Meaningful change of quality has appeared with emission GPS/GPRS (General Packet Radio Service) at transmission active geodetic network service. In 2004 year RTCM (Radio Technical Commission for Maritime Services) introduced NTRIP (Networked Transport of RTCM via Internet Protocol) which determined usage of VHF radio commonly implemented in RTK systems. NTRIP also determined usage of the other applications using wireless radio links in relation base receiver - rover receiver; their a few metres range made GNSS realisation and surface correction transfer (VRS, Max, FKP methods) impossible [14].

The standard RTCM 3.0 version has been recommended since 2004 [13]. Setting up in 2008 year active geodetic network service and meaningful quality change within the range of precise GPS (multi system receivers, frequency increasing till $20 \mathrm{~Hz}$, levelling geodetic model implementation) have induced interdisciplinary team of researchers to undertake study into GPS usability for geodetic railway services [10]. Satellite surveying will enable in future the actual state inventory as well as updated rough route marking out. Action towards creation the implementation base of a new measurement technique for railway should be undertaken. Presented work describes development of mains electricity measure techniques and measuring accuracy of railway satellite surveying on the ground of experimental research. Research relied on taking a few dozen kilometre railway detour by a motor truck WM 15 with four satellite aerials installed on its platform. The initiator of experimental research was Technical University of Gdansk, Polish Naval Academy Institute of Navigation and Maritime Hydrography). Technical support was given by Polish State Railways SA, Gdańsk (with its seat in Gdynia) and measuring apparatuses were given by Leica Geosystems GA.

\section{DEVELOPMENT OF GLOBAL POSITIONING SYSTEM}

Permanent observations GNSS implemented by large-area satellite network have been transformed into complex data communication system. They have offered 
not only post processing GPS services but also the provision of the correction data sent at real time. The first stages of their development were national passive systems created at the beginning of the 1990s, also in our country [1]. They have evolved from single reference stations located at technical universities to national systems. They were characteristic of autonomous station, lack of standardization within the range of unified report data replacement exploitation and local character of use [7]. As time passed by, passive systems gained differential function (GPS) of real time, becoming active structures - making DGNSS services possible. Meaningful broadening zone action, similar to nautical DGPS system, was connected with new telegram type RTCM (from version 2.0 to 3.0 up to date version) and mathematical simulation surface correction GPS development [13].

The first idea of creation permanent station network GNSS was prepared in 1995 on the initiative of two Commitees of Polish Academy of Siences (Commitee of Space Research and Commity of Geodesy) [2]. It was assumed that the network should be multifunctional and adapted not only to geodesy. In the consequence of different centres activity, the local stations were forming. They were created in Warszawa, Łódź, Gdańsk and at intensive mining industry area (Górny Śląsk, Lubińsko-Głogowski Okręg Miedziowy) [3]. Then a six-point network at Śląsk and a three-point network at the Three-City area were created [5].

The dominant world trend at the beginning of the 21 century was starting active national network activity, for example CORS, SAPOS, SWEPOS, OS-AGN (fig. 1).

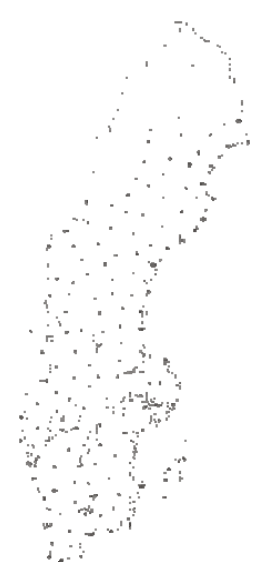

a)

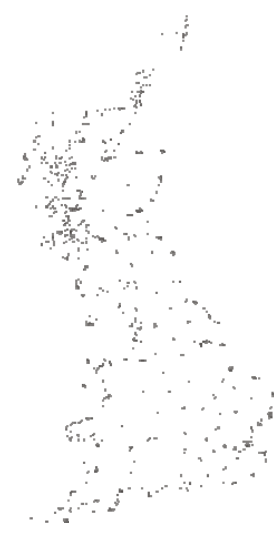

b)

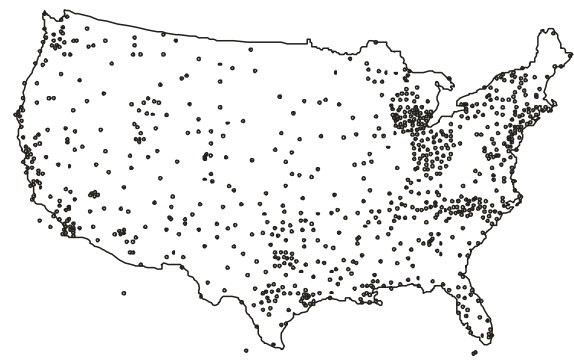

c)

Fig. 1. Architecture of chosen active geodetic networks:

a) SWEPOS - Sweden; b) OS-AGN - Great Britain; c) CORS - USA [own study]

The networks offered users payable or unpaid services as well as payable real time services $[6,12]$. Modernity of network techniques, compared to classical 
coordinates determination with exploitation single reference station and movable receiver in RTK method, lies among other things in implementation of correction using virtual reference station VRS [8]. It enables working out of pseudo-distance correction dedicated to receiver coordinates [11].

In 2007 year Główny Urząd Geodezji i Kartografii realised Active Geodetic Network ASG-EUPOS which is the national permanent GNSS stations network offering services for geodesy and navigation [4].

\section{POLISH ACTIVE GEODETIC NETWORK}

In the 1990s Central and East European countries started setting up DGNSS stations. They were not compatible with the West European stations. In Berlin, in 2002 was taken a decision about European Position Determination System development in the direction of the East. The Polish part of the system ASG-EUPOS has consisted of 98 reference stations evenly located over country(fig. 2). Except for the new starting up stations, the system has adapted also existing stations managed by universities, research and development centres, state administration and private firms. At the present moment ASG-EUPOS is composed of the next reference station groups: 84 stations with GPS module and 14 stations with GPS/GLONASS module. Additionally the system has cooperated with nearly 30 foreign stations.

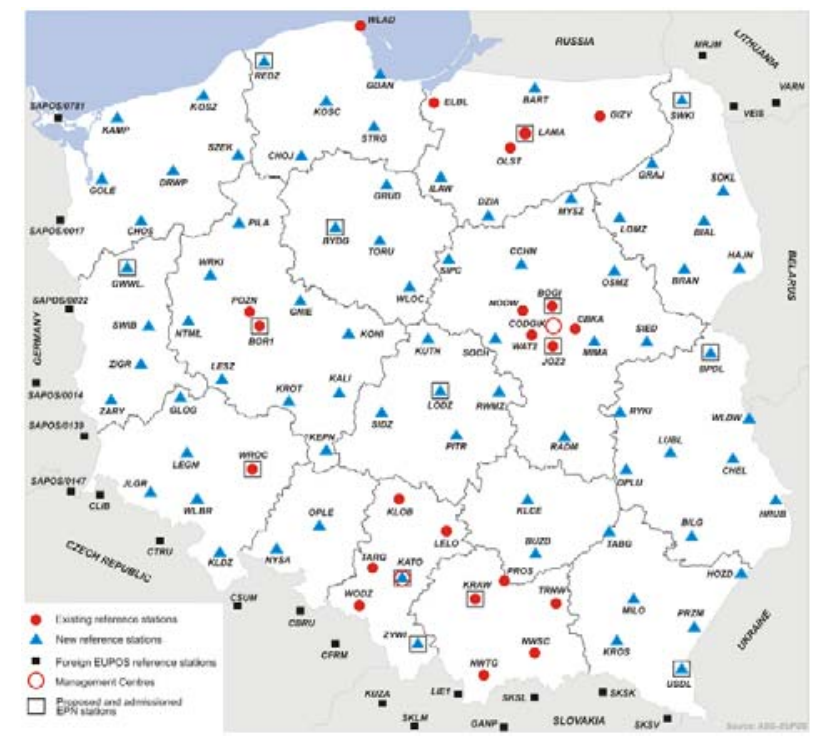

Fig. 2. Location of the reference station system ASG-EUPOS [own study] 
National Management Centres, called also Counting Centres are the second segment of ASG-EUPOS system. Central Office is in Warszawa and its branches are in Katowice. They have a task of controlling and managing stations network, correction generating of made observations and making satellite surveying available to the recipients. All interferences are signalled and analysed; if necessary countermeasures have been undertaken. Both Counting Centres are redundant in the range of done services. Beside position surveying services Counting Centre has maintained reference system. Weekly control makes possible supervising the invariability of points defined the system. The highest number of users served by Counting Centre is 1200 . Users making use of centre services at provision correction data real time exploit mainly Internet and GSM. Corrective information is sent to users via Internet using specially elaborated NTRIP protocol. GSM has used package data transfer GPRS. Working far from the cities can present a problem of being out within range of one or even all mobile communications operators. Because of that, users who want to take advantage of the provision correction data should have SIM cards of a few operators.

\section{RAILWAY MEASUREMENTS}

In 2009, at the Gdansk University of Technology and Polish Naval Academy there have been carried out, for the first time, continuous satellite surveying of railway track by the use of the relative phase method based on geodesic active network ASG-EUPOS and NAVGEO service. Still continuing research works focused on the GNSS multireceivers platform evaluation for projecting and stock-taking. Next year the same team repeated similar measurements (07.04.2010) on the railroad between two Gdansk stations (Gdansk-Central and Gdansk New Port). Three Leica GPS Total station system 1200 SmartRover (with ATX1230 GG antennas) receivers were located in the diameter of the platform (fig. 3). Polish Active Geodetic Network ASG-EUPOS was used as a reference network transmitted Real Time Kinematic Positioning Service according to RTCM 3.1. standard.

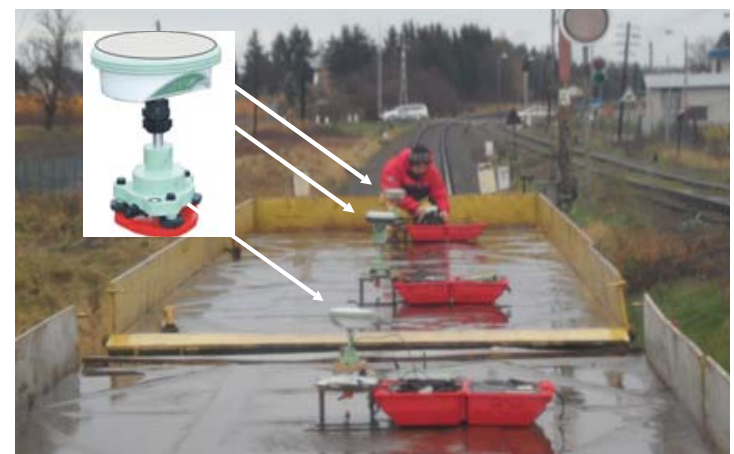

Fig. 3. GPS Total station receivers location on the platform [own photo] 
For the best measurement time period determination software Leica Survey Design was used.

\section{ACCURACY EVALUATION}

In order to evaluate accuracy characteristics of different GNSS methods received positions were recorded. Data files were containing position time series in the format of NMEA 0183 standard, GGA referenced to WGS-84 datum ( $a=6378137.00 \mathrm{~m}, b=6356752.314 \mathrm{~m}$ ). The World Geodetic System 1984 (WGS84) datum is based on the WGS84 ellipsoid which only exhibits a small difference in the flattening parameter compared to the GRS80 and therefore both ellipsoids can be assumed identical for most practical purposes. Measured ellipsoidal coordinates were transformed to Gauss-Kruger $(\mathrm{X}, \mathrm{Y})$ conformal coordinates, based on relations.

$$
\begin{aligned}
y=R \cdot & {\left[d L \cos (B)+\frac{d L^{3}}{6} \cos (B)^{3}\left(1-t^{2}+\eta^{2}\right)+\frac{d L^{5}}{120} \cos (B)^{5}\left(5-18 t^{2}+t^{4}+14 \eta^{2}-58 \eta^{2} t^{2}\right)\right] } \\
x & =k \cdot R\left[\frac{S(B)}{R}+\frac{d L^{2}}{2} \sin (B) \cos (B)+\frac{d L^{4}}{24} \sin (B) \cos (B)^{3}\left(5-t^{2}+9 \eta^{2}+4 \eta^{4}\right)+\right. \\
& \left.+\frac{d L^{6}}{720}\left(\sin (B) \cos (B)^{5}\right) \cdot\left(61-58 t^{2}+t^{4}+270 \eta^{2}-330 \eta^{2} t^{2}\right)\right]
\end{aligned}
$$

where:

$B, L \quad$ - measured ellipsoidal coordinates;

$R \quad$ - radius of curvature in the prime vertical;

$S(B) \quad$ - distance from the equator to defined coordinate $B$;

$d L \quad$ - difference in longitude between $L$ and prime meridian;

$k=0.999923-$ scale factor.

Others parameters could be calculated as:

$$
\begin{gathered}
t=\tan (B) \\
\eta=\frac{e^{2} \cos (B)^{2}}{1-e^{2}}
\end{gathered}
$$

where:

$e$ - eccentricity of ellipsoid;

$\eta$ - orientation angle of distortion ellipsis. 
On the basis of the obtained results it was possible to define the main direction of the whole railway route and its segments. These are basic data to design a railway geometric system. For that purpose, a particular run of the route was examined on railway segments. One of the segments - straight line (230 fixes) was used for regression analyses. All calculations were realized in Mathcad, software version 13. Least Squares Method were used for analyses (LSM).

\section{Weighted Least Square Method}

The better estimate than Least Square Method can be obtained using weighted least squares (WLS), also called generalized least squares (GLS). Weighted least squares come from different sub-populations for which an independent estimate of the error variance, if available. The idea is to assign to each observation a weight that reflects the uncertainty of the measurement. In general, the weight $p_{i}$ assigned to the $i$ th position observation $y_{i}, x_{i}$, will be a function of the variance of this observation. For railway measurements each GPS solution was characterized by $2 \mathrm{D}$ and $3 \mathrm{D}$ position standard deviation. The linear regression function can be estimated by finding values of $a$ and $b$ minimalizing:

$$
p_{i}\left(x_{i}-\bar{x}_{i}\right)^{2}=\sum_{i=1}^{n} p_{i}\left[x_{i}-\left(a+b y_{i}\right)\right]^{2}=\min
$$

The estimated line coefficients (slope and intersection) $a, b$ can be calculated as follows:

$$
\begin{aligned}
& \bar{a}=\frac{\sum_{i=1}^{n} p_{i} x_{i} \sum_{i=1}^{n} p_{i} y_{i}-\sum_{i=1}^{n} p_{i} \sum_{i=1}^{n} p_{i} x_{i} y_{i}}{\left(\sum_{i=1}^{n} p_{i} x_{i}\right)^{2}-\sum_{i=1}^{n} p_{i} \sum_{i=1}^{n} p_{i} x_{i}^{2}} \\
& \bar{b}=\frac{\sum_{i=1}^{n} p_{i} x_{i} \sum_{i=1}^{n} p_{i} x_{i} y_{i}-\sum_{i=1}^{n} p_{i} y_{i} \sum_{i=1}^{n} p_{i} x_{i}^{2}}{\left(\sum_{i=1}^{n} p_{i} x_{i}\right)^{2}-\sum_{i=1}^{n} p_{i} \sum_{i=1}^{n} p_{i} x_{i}^{2}}
\end{aligned}
$$

All GNSS recorded track had 3924 m (one way), but for analyses the straight line $(200 \mathrm{~m})$ was chosen. The lower figure present plot of positions determined by six GNSS receivers on the same 200 meters part of the rail road. 


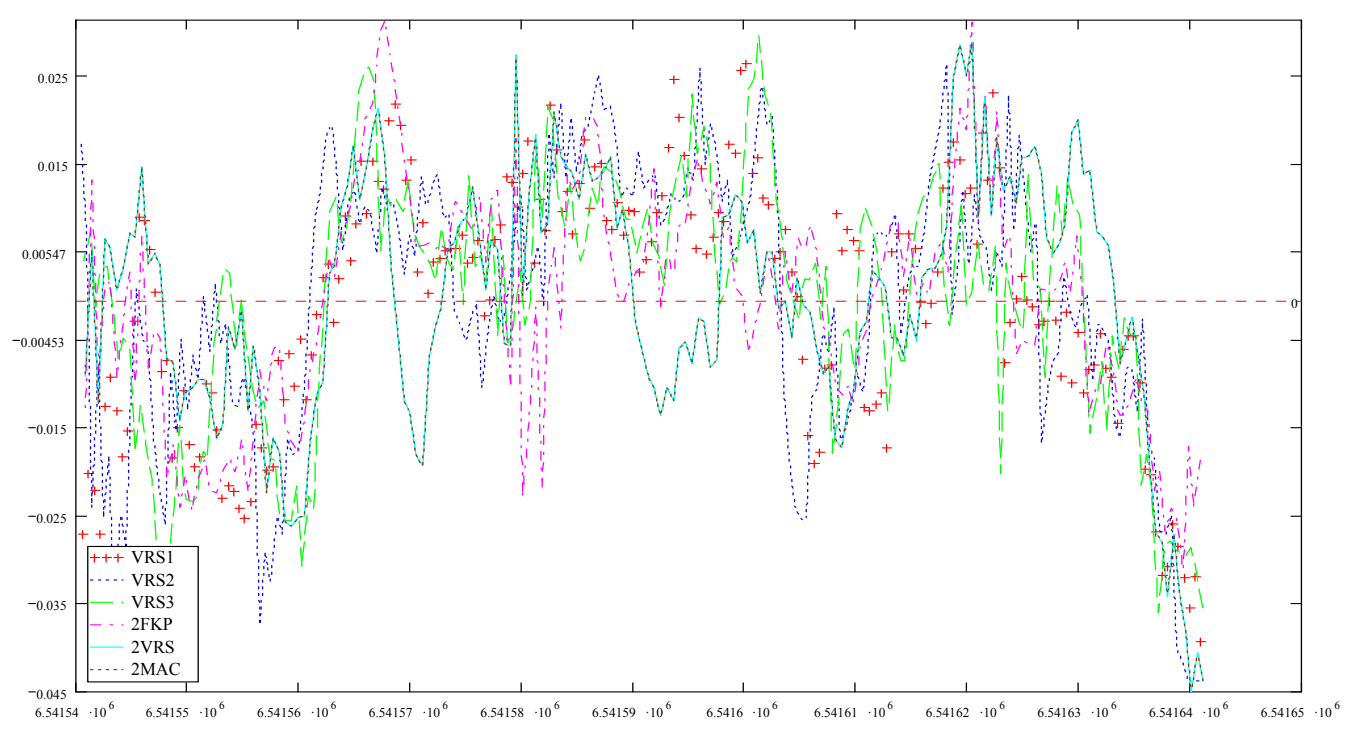

Fig. 4. Positions determined by six GNSS, receivers on the same 200 meters part of the railroad [own study]

Application of the Weighted Least Square Method allows railway track line determination with accuracy $1-1.5 \mathrm{~cm}$ (fig. 5).

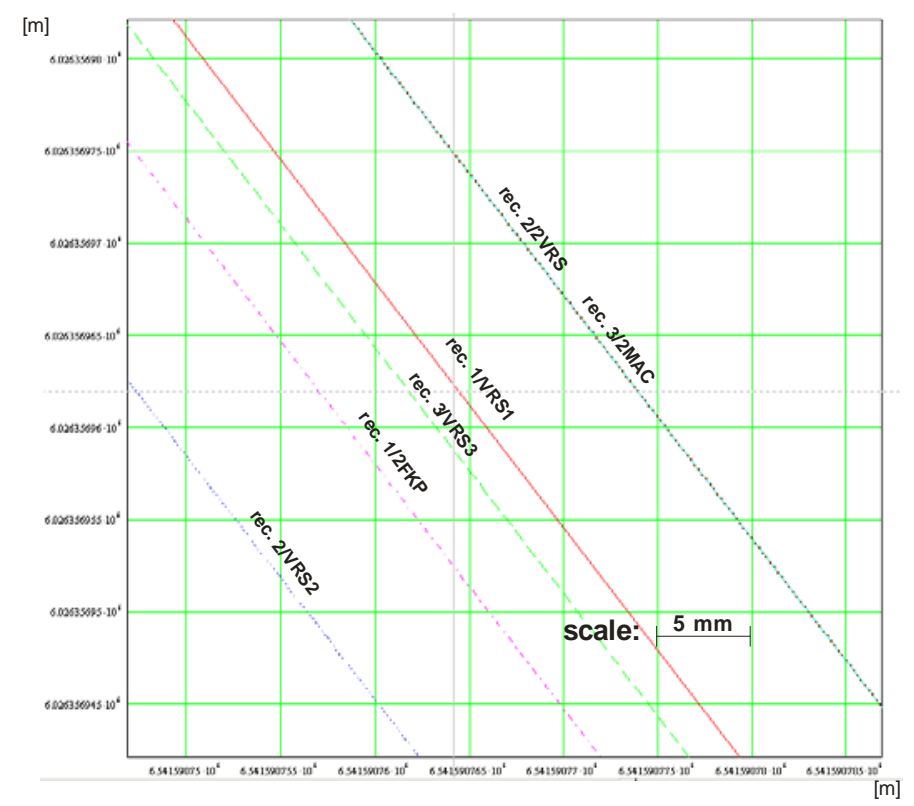

Fig. 5. Railway Track determined lines calculated by Weighted Least Square Method [own study] 


\section{Low-Pass Filtering}

Detailed analysis of the recorded measurement signal (after the transformation described earlier) leads to the conclusion that the signal gives not only information about the shape of track, which is characterized - by definition - by smooth curvatures. There is also a signal component which states a result of errors associated with the vibration of the moving vehicle as well as measurement errors. In order to analyze the measurement signal in the frequency domain, Fourier transformation was used. As the analyzed signal has discrete character, it has been used the so-called Discrete Fourier Transformation of the series of the measurement samples. The transformation is described by the formula:

$$
X_{k}=\sum_{n=0}^{N-1} x_{n} \cdot e^{-\frac{2 \pi i}{N} n k} \quad k=0, \ldots, N-1
$$

where:

$X$ - transformation result;

$x \quad$ - signal's samples.

Modern algorithms for solving this problem, allow significant reduction in computing time. The most popular algorithm is the fast Fourier transformation of the base of 2. It reduces the number of operations from $O\left(N_{2}\right)$ to $O\left(N \log _{2} N\right)$. But to take advantage of this algorithm, it is necessary to prepare the data vector by establishing the right size of it, namely the number of samples should be $2^{\mathrm{k}}$, where $\mathrm{k}$ is a natural number. In order to analyze the signal in the frequency domain Scilab environment was used. In the libraries of functions there are implemented functions of the Fourier transformation as well as the inverse transformation to the original domain. Written by the authors calculating script was based on the following algorithm:

- load the matrix of measurement signal (from a text file);

- extend the matrix to the size of $2^{\mathrm{k}}$ (empty positions of vector set as zero);

- create a vector of the frequency basing on the signal sampling frequency;

- perform and display the resulting FFT transform;

- specify the parameter of a low-pass filter and filter the transformed signal;

- perform the inverse transformation of the signal subjected to filtration and view the result on the background of the original signal.

Figure 6 shows the result of transformation (FFT). Assumed low-pass filter with a cutoff frequency $0.15[1 / \mathrm{m}]$. This value is matched only by the qualitative assessment by the reverse transformation on the background of the input signal. 


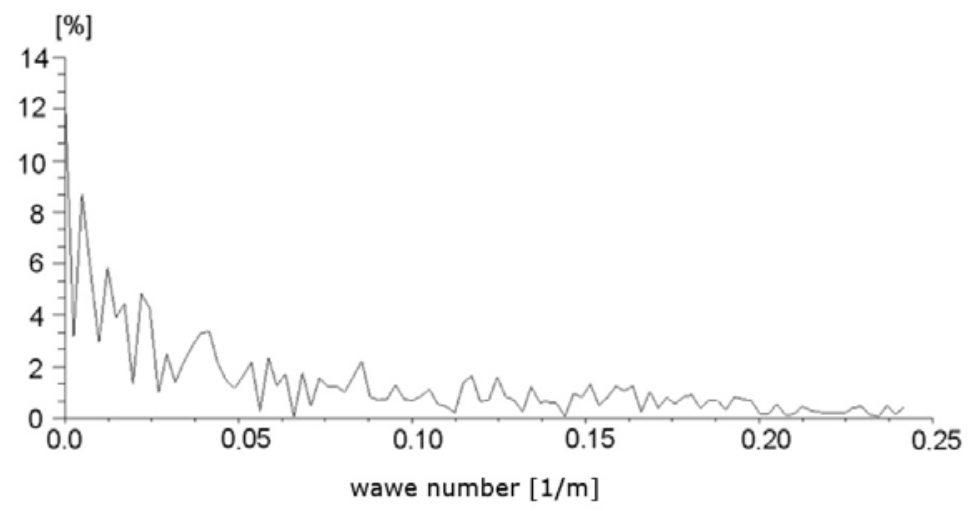

Fig. 6. Fourier transform for the analyzed section of the railway line [own study]

As follows from the above algorithm and the presented results, the proper selection of the filter (its kind) and defining its parameters played a large role. At this stage, the authors do not yet determine the criteria that would allow automatic control of the filter and therefore the results presented are subject to uncertainty of a loss of certain ranges of frequencies that affect the geometry of the analyzed track. Figure 7 shows a comparison between the original signal and filtered one.

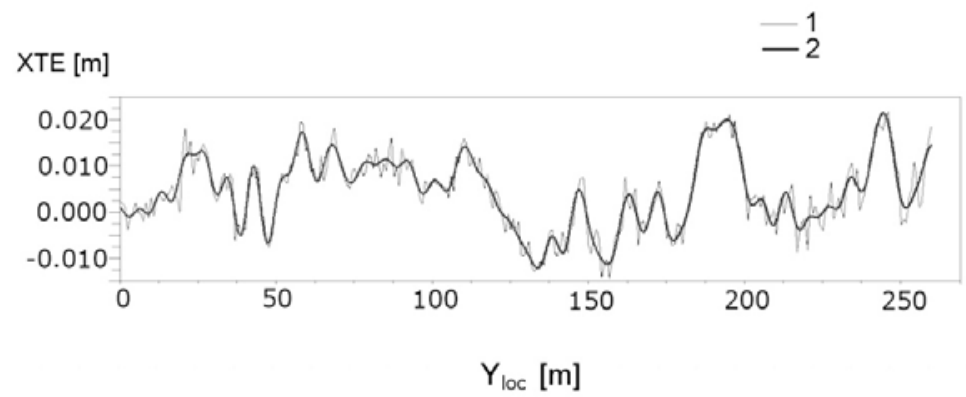

Fig. 7. Comparison of the signal before and after filtration: $1-$ signal before filtering; 2 - signal after filtering by low-pass filter with cutoff wave number of $0.15[1 / \mathrm{m}]$; XTE - means Cross Track Error [own study]

If we assume that the filtered signal brings us closer to the real shape of the actual track, the difference between the both filtered and original signals will illustrate the measurement error. The signal for this deviation for the length of the analyzed section of the track is performed in fig. 8. The analysis shows that these values are small, their average value is $1.53 \mathrm{~mm}$ with a standard deviation equal to $1.22 \mathrm{~mm}$. 


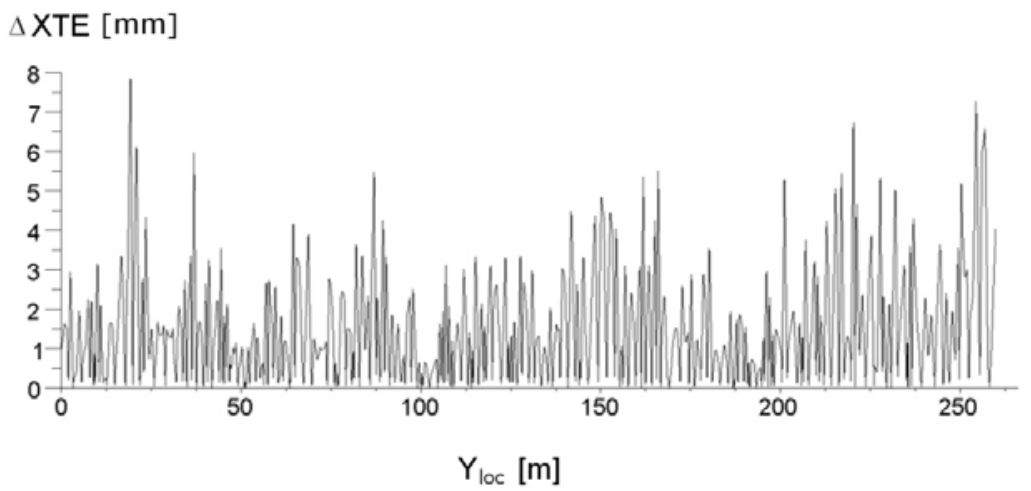

Fig. 8. The absolute values of deviations between the signal before and after filtration [own study]

\section{The use of Chebyshev Filter}

Another approach to the problem of filtering the signal used the Chebyshev filter 2, 3, 4 and 6th order of IIR infinite impulse response. The filter was checked for different values of the ratio of cutoff frequency $\omega_{c}$ to the sampling frequency $\omega_{p}$ (ranging from 0.01 to 0.3 ) as well as different slope in the transition band of $20 \mathrm{~dB}$. Filtration was performed according to the standard differential equation describing the IIR filter in the form as below:

$$
N X_{i}=b_{0} \cdot X_{i}+b_{1} \cdot X_{i-1}+b_{2} \cdot X_{i-2}+\ldots-a_{1} \cdot N X_{i-1}-a_{2} \cdot N X_{i-2}-\ldots
$$

The examples of utilized coefficients' values are performed in table 1, 2 and 3 .

Table 1. Coefficients of 2 nd order filter [own study]

\begin{tabular}{|l|c|c|c|c|c|}
\hline \multirow{2}{*}{$\omega_{\mathrm{c}} / \omega_{\mathrm{p}}$} & \multicolumn{5}{|c|}{ Coefficients of 2 nd order filter (for various $\left.\omega_{\mathrm{c}} / \omega_{\mathrm{p}}\right)$} \\
\cline { 2 - 6 } & $\mathrm{b}_{0}$ & $\mathrm{~b}_{1}$ & $\mathrm{~b}_{2}$ & $\mathrm{a}_{1}$ & $\mathrm{a}_{2}$ \\
\hline $\mathbf{0 . 0 1}$ & $\mathbf{8 . 6 6 3 3 8 7 e - 4}$ & $\mathbf{1 . 7 3 2 6 7 8 e - 3}$ & $\mathbf{8 . 6 6 3 3 8 7 e - 4}$ & $\mathbf{- 1 . 9 1 9 1 2 9}$ & $\mathbf{9 . 2 2 5 9 4 3 e - 1}$ \\
\hline 0.2 & $1.997396 \mathrm{e}-1$ & $3.994792 \mathrm{e}-1$ & $1.997396 \mathrm{e}-1$ & $-4.291048 \mathrm{e}-1$ & $2.280633 \mathrm{e}-1$ \\
\hline 0.3 & $3.8491163 \mathrm{e}-1$ & $7.698326 \mathrm{e}-1$ & $3.849163 \mathrm{e}-1$ & $3.249116 \mathrm{e}-1$ & $2.147536 \mathrm{e}-1$ \\
\hline
\end{tabular}

Table 2. Coefficients of 3rd order filter [own study]

\begin{tabular}{|l|c|c|c|c|c|c|c|}
\hline \multirow{2}{*}{$\omega_{\mathrm{c}} / \omega_{\mathrm{p}}$} & \multicolumn{7}{|c|}{ Coefficients of 3rd order filter (for various $\left.\omega_{\mathrm{c}} / \omega_{\mathrm{p}}\right)$} \\
\cline { 2 - 8 } & $\mathrm{b}_{0}$ & $\mathrm{~b}_{1}$ & $\mathrm{~b}_{2}$ & $\mathrm{~b}_{3}$ & $\mathrm{a}_{1}$ & $\mathrm{a}_{2}$ & $\mathrm{a}_{3}$ \\
\hline 0.05 & $1.213 \mathrm{e}-5$ & $3.638 \mathrm{e}-5$ & $3.638 \mathrm{e}-5$ & $1.213 \mathrm{e}-5$ & -2.9710 & 2.9607 & -0.989 \\
\hline 0.06 & $2.095 \mathrm{e}-5$ & $6.285 \mathrm{e}-5$ & $6.285 \mathrm{e}-5$ & $2.095 \mathrm{e}-5$ & -2.9608 & 2.9495 & -0.987 \\
\hline $\mathbf{0 . 0 8}$ & $\mathbf{4 . 9 6 0 e - 5}$ & $\mathbf{1 . 4 8 9 e}-4$ & $\mathbf{1 . 4 8 9 e}-4$ & $\mathbf{4 . 9 6 0 e - 5}$ & $-\mathbf{2 . 9 3 6 1}$ & $\mathbf{2 . 9 1 9 8}$ & $-\mathbf{0 . 9 8 3}$ \\
\hline 0.1 & $9.696 \mathrm{e}-5$ & $2.909 \mathrm{e}-4$ & $2.909 \mathrm{e}-4$ & $9.696 \mathrm{e}-5$ & -2.9055 & 2.8855 & -0.979 \\
\hline 0.2 & $7.930 \mathrm{e}-5$ & $2.379 \mathrm{e}-4$ & $2.379 \mathrm{e}-4$ & $7.930 \mathrm{e}-5$ & -2.7026 & 2.6991 & -0.995 \\
\hline
\end{tabular}


Table 3. Coefficients of 4th order filter [own study]

\begin{tabular}{|l|l|l|l|l|l|l|l|l|l|}
\hline \multirow{2}{*}{$\omega_{\mathrm{c}} / \omega_{\mathrm{p}}$} & \multicolumn{7}{|c|}{ Coefficients of 4 th order filter (for various $\omega_{\mathrm{c}} / \omega_{\mathrm{p}}$ ) } \\
\cline { 2 - 10 } & $\mathrm{b}_{0}$ & $\mathrm{~b}_{1}$ & $\mathrm{~b}_{2}$ & $\mathrm{~b}_{3}$ & $\mathrm{~b}_{4}$ & $\mathrm{a}_{1}$ & $\mathrm{a}_{2}$ & $\mathrm{a}_{3}$ & $\mathrm{a}_{4}$ \\
\hline $\mathbf{0 . 0 1}$ & $\mathbf{4 . 1 5 e - 7}$ & $\mathbf{1 . 6 5 9 e - 6}$ & $\mathbf{2 . 4 8 9 e - 6}$ & $\mathbf{b}_{1}$ & $\mathbf{b}_{\mathbf{0}}$ & $\mathbf{- 3 . 8 9}$ & $\mathbf{5 . 6 8 8}$ & $\mathbf{- 3 . 6 9 5}$ & $\mathbf{0 . 9 0 1}$ \\
\hline 0.075 & $9.73 \mathrm{e}-4$ & $3.890 \mathrm{e}-3$ & $5.835 \mathrm{e}-3$ & $\mathrm{~b}_{1}$ & $\mathrm{~b}_{0}$ & -3.10 & 3.774 & -2.111 & 0.456 \\
\hline
\end{tabular}

The results of filtration are shown in figure 9. Despite the fact that filtering of the signal with the use of equation (9) does not require the transformation to the frequency domain, the assumption of the appropriate coefficients of the equation for Chebyshev filters states a critical and difficult task. Furthermore, this filter is characterized by an unsatisfactory response phase, what is clearly visible in fig. 9. In the presented considerations, this fact may result in an additional uncertainty of estimating the actual position of the railway track in the adopted coordinate system.

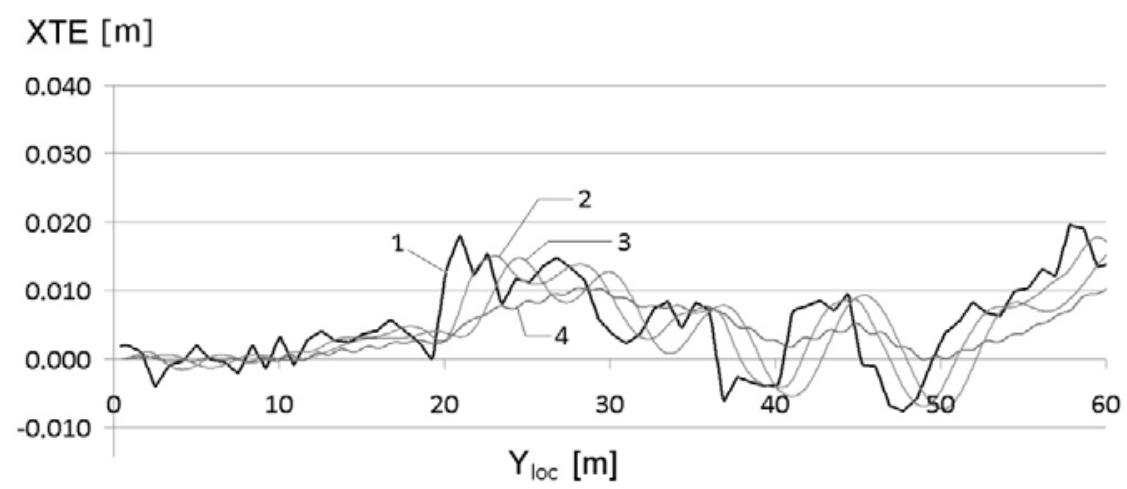

Fig. 9. Comparison of the filtaration results of analyzed signal (a part) using of Chebyshev

Type II filters: 1 - signal before filtering; 2 - Chebyshev filter of 2 nd order with $\omega_{\mathrm{c}} / \omega_{\mathrm{p}}=0.01 ; 3-$ Chebyshev filter of 4th order with $\omega_{\mathrm{c}} / \omega_{\mathrm{p}}=0.01 ; 4-$ Chebyshev filter of 3rd order with $\omega_{\mathrm{c}} / \omega_{\mathrm{p}}=0.08$ [own study]

\section{CONCLUSIONS}

The authors believe that a radical improvement in the process of geometrical designing of a railway track will be available after the application of continuous satellite measurements with GPS receivers installed on a moving rail vehicle. Such methodology of measurements will allow reconstructing the position of the track axis in an absolute system of coordinates, and the number of recorded samples in output data will depend only on the established sampling frequency of the signal. 
To determine the location of straight sections of the track may the concept XTE (Cross Track Error), existing in navigation terminology, be used, which states a measure of the error position of a moving object. In the analyzed case the XTE is also applied to the uncertainty associated with the technique of measurement.

In order to evaluate the accuracy of determining the axis of the railway track by satellite surveying, obtained XTE signal must be analyzed in order to separate the signal's components which result from measurement error, not having a direct relationship with the shape of the measured track. As indicated initially, the use of Fourier Transform (FFT) gives optimistic results in this field.

In the presented computational examples, the authors found that the differences between measured values and the values after applying the filtering in post-process (representing the approximation of the actual track shape) were very small (i.e. a row of single millimeters). The fact can indicate a high-precision position determinations using continuous satellite measurements and their applicability for the design and inventory of the railway track.

\section{REFERENCES}

[1] Baran W., New National System of Geodetic Coordinates in Poland, Geodezja i Kartografia, 1994, Vol. XLIII, No. 1, pp. 41-49.

[2] Baran L. W., Zieliński J. B., Active GPS Stations as a New Generation of the Geodetic Network, Geodezja i Kartografia, 1998, Vol. XLVII, No. 1-2, pp. 33-40.

[3] Baran L. W., Oszczak S., Zieliński J. B., The utilisation of space techniques in geodesy and in navigation in Poland (in Polish), Nauka, 2008 , No. 4, pp. 43-63.

[4] Bosy J., Graszka W., Leonczyk M., ASG-EUPOS The Polish Contribution to The EUPOS Project, Symposium on Global Navigation Satellite Systems, Berlin, 11-14 November 2008.

[5] Ciećko A., Oszczak B., Oszczak S., Determination of Accuracy and Coverage of Permanent Reference Stadion DGPS/RTK in Gdynia, Proceedings of the 7th Bilateral Geodetic Meeting Italy - Poland, 22-24 May 2003, Bressanone, Italy, Reports on Geodesy, 2003, No. 2, pp. 45-51.

[6] Cord-Hinrich J., SAPOS-Part of a Geosensors Network, Symposium on Global Navigation Satellite Systems, Berlin, 11-14 November 2008.

[7] Dziewicki M., Felski A., Specht C., Availability of DGPS Reference Station Signals on South Baltic, Proceedings of the 2nd European Symposium on Global Navigation Satellite Systems — GNSS '98, Toulouse, France, 1998. 
[8] Gocał J., Strach M., The apply of RTK in engineering - GPS receivers on tracs (in Polish), Geodeta, 2004, No. 5.

[9] Koc W., Specht C., Results of satellite measurements of the railway tracs (in Polish), Technika Transportu Szynowego, 2009, No. 7-8.

[10] Koc W., Specht C., Jurkowska A., Chrostowski P., Nowak A., Lewiński L., Bornowski M., Qualifying of the course of the railway-route in the way of satellite measurement (in Polish), II Scientific-Technical Conference 'Designing, the construction and the maintenance of the infrastructure in the rail transport', INFRASZYN 2009, Zakopane 2009.

[11] Landau H., Vollath U., Xiaoming Chen, Virtual Reference Stations versus Broadcast Solutions in Network RTK - Advantages and Limitations, GNSS Conference 2003, Graz, Austria, April 2003.

[12] Rizos C., Yan T., Omar S., Musa T., Kinlyside D., Implementing network-RTK: the SydNET CORS infrastructure, The 6th International Symposium on Satellite Navigation Technology Including, Mobile Positioning \& Location Services, Melbourne SatNav 2003, Australia, 22-25 July 2003.

[13] RTCM Recommended Standards for Differential GNSS (Global Navigation Satellite Systems) Service, Version 3.0, RTCM Paper 30-2004/SC104-STD, 2004.

[14] RTCM Recommended Standards for Network Transport of RTCM via Internet Protocol (NTRIP), Version 1.0, RTCM Paper 200-2004/SC104-STD, 2004.

Received May 2012

Reviewed September 2012 